\title{
Chapter 2: \\ The Medium of the Museum
}

\subsection{Museum Space and the 'Ideal' Visitor}

How do history museums approach the past? Aleida Assmann - partially drawing on the museum analysis of Rosmarie Beier-de Haan - differentiates between three types of historical representations of memory: narrating, exhibiting, and staging (2007, 149-153). ${ }^{1}$ Narrating refers to the narrative semantics of a historical representation that ascribes meaning, importance, and direction to the narrated events. Exhibiting refers to the placement of historical texts, images, and objects in space, which is far less sequential and causal than narrating and allows for effects of simultaneity. Finally, staging the past is divided into the categories of media staging, particularly through film and moving images, and spatial staging, which Assmann mainly relates to authentic heritage spaces that allow for imaginative re-experiencing or performative simulations of the past. However, Assmann's analysis is not specific enough to help us understand the particularities of the medium of the 'museum' (or exhibitions in museum space). In her chart - which is divided into basic representational modes, media, and format - the museum as a 'format' only appears to be connected to the mode of exhibiting, whereas 'medial staging' relates to documentary and historical film, and 'spatial staging' to memorial sites and reenactments of history $(2007,154)$.

While Assmann's typology, terms and structural descriptions of 'staged' public history are slanted toward the production sites of narratives, museum exhibitions, or performances, narratologists have broadened the subject-matter of narratology to cultural representations in general (see e.g. Nünning and Nünning 2010). Ansgar Nünning has shown how the focus on world-making allows for the discussion of historiographic narrative in the much wider contexts of media and discourse theory, if one, for example, sees "events, stories, and storyworlds as discursively created, medially represented, culturally specific and historically mutable constructs" (Nünning 2010, 206). To apply this to an understanding of representational forms and storyworlds of history museums and the specifics of the museum as medium the potential visitor must be taken into account - at least as much as the motivation and intentional design of the exhibition creators. The question of whether museums can be read like a text has caused considerable debate, particularly among narratologists and semioticians on the one hand, and museum stud-

1 In German erzählen, ausstellen, and inszenieren.

Ә OpenAccess. (C) 2020 Stephan Jaeger, published by De Gruyter. (cc) BY-NC-ND This work is licensed under the Creative Commons Attribution-NonCommercial-NoDerivatives 4.0 License. 
ies scholars and museum practitioners on the other. In comparison to a more general reader response theory that relates to textual media, one must here ask what specific role the visitor has in history museums' representations, narrations, staging, and simulations of the past? What does it mean when the visitor moves through space and spatial arrangements, in comparison to the reader of a book who must imagine the spaces being narrated?

Space in museums can also be described through a narratological approach that has recently emerged: 'narrative geography.' Marie-Laure Ryan, Kenneth Foote, and Maoz Azaryahu define space as denoting "certain key characteristics of the environments or settings within which characters live and act: location, position arrangement, distance, direction, orientation, and movement" (2016, 7). Regarding this concept, the museum functions as a core example for spatial narrative media. However, its discussion does not explain the specificity of museum narratives in space, beyond the general observation that museums speak to the visitor's different senses. After the authors explain numerous possibilities of how narrative can play a role in spatial museum design, their chapter on "museum narrative" goes on to explore fairly broad spatial storylines in narrativebased museums, narrative architecture in history museums, and the framing of museum narratives through beginnings and endings. Finally, Ryan et al. argue that the museum's main characteristic in terms of narrative geography can be found in its difference from landscape narratives: "the possibility to design the exhibit along a circulation path that accords with a storyline and narrative progression" $(2016,203)$. However, even if memorial sites deal with the physical conditions that they find in pre-existing buildings or landscapes, the complexity of museum representation is clearly restricted through numerous discursive and political conditions. The complexity of demands made by the architectural design, the design firm itself, museum stakeholders, marketing pressures, lobbyists who want their themes represented, local and national politicians, and the press are such that one wonders how free museums actually are to narrate space. A narratological theory of space derived mainly from categories that have been developed for the literary analysis of fictional texts seems to fall short in explaining narrative and space within the museum.

To explain the relationship of museum and space, Daniel Tyradellis identifies exhibitions with "thinking in space" (2014, 134-159). Kirshenblatt-Gimblett notes that "[e]xhibitions are fundamentally theatrical, for they are how museums perform the knowledge they create” (1998, 3). Similarly, Heike Buschmann follows Michel de Certeau in reading 'space' as the result of the interaction between a person and the structural condition provided in the three-dimensional 'place' (2010, 162-163). This acknowledges that the museum needs the entity of the recipient to actualize or perform its space, and furthermore, that it is nec- 
essary to understand the role of the visitor in space and to illustrate the poietic and performative nature of museum exhibitions, in analyzing how exhibitions represent the past. Poiesis - a prominent concept in the historiographical theories of Hayden White (1987: 42; see also Jaeger 2011, 33-34) and Paul Ricœur (1984-85, I: 52-87) - means that the past only becomes reality through the act of representation or narration. This is particularly evident in the medium of the museum, where the museum first creates a spatial arrangement of objects, images, texts, and scenes; and secondly, it requires the (active) perception of visitors to complete the process of experientiality and fill the shell of the exhibition. This second element surpasses White's and Ricœur's use of the term, wherein they emphasize the poietic potential of historiographic narrative.

To understand this aspect of the museum visitor's role, Mieke Bal's comparison between visitors of the theater and of art exhibitions proves helpful: "Instead of standing still in front of an imaginary stage, as in theater, the visitor now walks through a forest of objects. And instead of being a spectator of the play, she is now a co-narrator, fulfilling in her own way the script that predetermines the parameters within which the story can be told" (2008, 20, see also 1996, 2-4). Bal's approach emphasizes the dynamics that a museum visitor can perform in space, by zooming in and out like a film camera, from long shot to a close-up and vice versa $(2008,26){ }^{2}$ Similarly, Rosmarie Beier-de Haan's discussion of staging as an integral part of 'new museology' helps in defining the specifics of the museum as medium. Traditionally, museums have tried to create exhibitions that positioned the visitor as a detached observer (2006, 192). As part of 'new museology,'

[v]iewers are now drawn into the ensemble of exhibited objects, no longer able to assume the position of detached museum-goers hovering above or outside the exhibition. The viewers and their potential perceptions are now taken into account; they become part of the ensemble and are challenged to express their own perceptions, judgments, and emotions. (Beier-de Haan 2006, 192-193)

Suzanne MacLeod also points out both how the visitor's individual use and experience of space surpasses any intentional approaches that architects, interior designers, and curators in developing specific effects of space and architecture:

In the museum then, a range of users - professionals, researchers, families, tourists, organized groups, repeat visitors and so on - must also be recognized as continually remaking the architecture of the museum through the uses to which it is put. Such uses are, to a great extent of course, closely controlled by the individual and organizational visions of museum

2 See the discussion of 'historical distance' below. 
space dominant at any particular moment. This said, most of us could probably call to mind a memory of a museum space suddenly transformed through the uses to which it was put, even if it did return to its established character with its requisite spatial practices soon afterwards. (MacLeod 2005, 20)

In the museum context, design (the planning and building of a museum space) and reception (by the visitors who fill the space with their own expectations, decisions, and reactions) cannot be completely isolated from one another. Another concept utilizing space is assemblage theory. It surpasses the agency and intentional authorship of the museum planners and of the visitor and looks at assemblages or clusters that constitute discursive meanings in which the museum emerges (Macdonald 2013, 5-7). Adam Muller highlights the "dynamic interaction / intersection of overlapping clusters of objects, spaces, ideologies, memories, feelings, structures, histories, and experiences" (2019). Understood as 'assemblages,' these clusters are dynamic, open systems that lie partially beyond the scope of formal agency, such as that exercised by curators and museum administrators. External conditions, like a military's engagement in a contemporary war, or the European migrant 'crisis,' can completely change the perception of a pre-conceived exhibition design. Emma Waterton and Jason Ditmer combine assemblage and affect theory in their analysis of the Australian War Memorial in Canberra, conceptualizing it in terms of: "how designed museum spaces, exhibitions, landscapes, lighting, sound and visiting subjects, along with the predictive power that some of these are afforded, work together in the here-and-now to produce a range of possibilities" $(2014,136)$. Unlike Muller, they center their analysis - based on ethnographic visitor observation in actual museum spaces - around the interior spaces and scenes of an exhibition and stress an element of the 'unforeseeable' in the shifting actualities of the museum space during visitors' interactions with it (Waterton and Ditmer 2014, 136).

In reality, different visitors will react differently to each museum display, based on, among other things, their background, their intentions and interests, and the conditions of the actual visit (Hooper Green 2006; Falk 2009; Kirchberg 2010; Falk and Dierking 2012; Schröder 2013). Whereas empirical visitor analysis can certainly demonstrate important patterns that help museums understand an exhibition's effects, this study utilizes an aesthetic response theory ${ }^{3}$ in analyzing the semiotic and aesthetic potentialities of the museum space that an 'ideal' visitor can evoke, even if an actual visitor will only realize parts of it. Jennifer Hansen-

3 For its origins in literature analysis, see Iser 1978 (1976). See also Wolfgang Iser's discussion of the necessary interaction between mimesis and performance and the concept of 'staging' as an anthropological category (1993 [1991], 281-303). 
Glucklich uses the concept of the 'ideal visitor' as a way of understanding the "a visual language" each museum creates, "inscribed in its architecture, exhibits, objects, and spaces, to construct a particular visitor to its unique space. This visitor, like the novelist's 'ideal reader,' does not exist empirically. Rather, he or she is an ideal composite - fashioned through the language of the museum and made sympathetic to the salient worldview of the museum's host culture" (Hansen-Glucklich 2014, 10).

While this is a very useful description of the ideal reader/visitor concept, my approach is considerably more focused on the potentialities of an exhibition's spatial language than on the intended ideal visitor imagined by museum planners. Even if a museum intends to have their visitors react in a certain way, an approach that relies on the method of 'thick description,' can consider the performative nature of exhibition more precisely. ${ }^{4}$ In the context of representations of the Second World War, Zuzanna Bogumił et al. recently utilized such an approach to understand the representation of the 'enemy' in three city museums in St. Petersburg, Warsaw, and Dresden (2015). They provide a 'close reading' of the politics and poetics of display, power relations, agency, semiotics, narrative, aesthetics, and the construction of knowledge (2016, 14-15). ${ }^{5}$

In summary, beyond Bal and Hansen-Glucklich's 'ideal visitor,' it seems important to consider the specificity of the medium of the museum in space, and its performative and poietic nature - as distinct from text. Newer empirical visitor studies can function as complex identity studies or consider the actualities of individual and, consequently, varying museum experiences. In contrast, the aesthetic, response-based 'ideal visitor' approach allows us to understand both the different potential interpretations an exhibition holds and the techniques it employs to foreclose certain kinds of interpretation, manipulating its visitors toward accepting a specific interpretation and meaning of the past. On the one hand, such an analysis might confirm strategies and storylines that were implied by the creators of a museum. On the other, it can go beyond such agency and intentionality and in doing so, demonstrate the structural potential of an exhibition space to be read in specific or in various ways. ${ }^{6}$

4 This method was developed by cultural anthropologist Clifford Geertz [2017 [1973]) and applied to museum studies in the wake of the discussion of 'new museology' (Vergo 1989; Macdonald and Fyfe 1996; Macdonald 1998; Witcomb 2003; Beier-de Haan 2005).

5 In general, see also Gable 2005, 2010; Scholze 2004, 2010, for ethnographic and semiotic close readings of history museums.

6 Charting the paths and interpretations of actual visitors goes beyond this study and its methodology, yet such approaches can easily connect to this one, as Waterton and Dittmer do, in their 
In order to further understand the difference between the museum and other media and to reflect on the main representational parameters of historical (Second World War) exhibitions, it is useful to follow Thiemeyer's utilization of Marshall McLuhan's theoretical framework of hot and cool media (Thiemeyer 2010a, 247). Hot media - a category under which McLuhan also includes photography are so detailed that the visitor only passively perceives the singular version of the past being represented. In contrast, cool media have little visual information and require the active engagement of a visitor using their own imagination (McLuhan 1965 [1964]). The latter allows for distance between recipient and historical subject matter; the former seduces the visitor into following a pre-described path to understanding the past. At first glance, the medium of the museum, and in particular historical museums, seems to be a cool medium. This is due to that fact that visitors can choose their own paths through the museums, select what texts, images, objects, and installations they focus on. Depending on their background and expectations, there will be infinite ways of performing actual museum visits.

Yet, upon closer examination, this shows that the museum is a composite medium assembling and combining other media and potentially speaking to several of the visitor's senses; curatorial strategies can make the museum a hot medium that shapes narratives and experiences in specific, predetermined ways, as much as they can keep visitors at a distance and allow for reflection and contemplation. As a hot medium, the museum can steer and manipulate the visitor's emotions. As a cold one, it allows the visitor distance and relies on the visitor's participation. Thiemeyer is strongly critical both of experiential approaches that pretend to mimetically imitate the past and the suggestion of authenticity via sensual evidence. Consequently, he highlights the value of actual objects and the need for critical contextualization of images and objects (2010a, 248-253, 264-266; see also Jaeger 2019, 54-55).

Unlike Thiemeyer, Williams sees cool media as mainly illustrative. However, he similarly affirms that, "we can call those objects that may lack self-evident attachment to the narrative at hand, but possess a high emotional quotient and hence lend themselves more easily to emotive spectacle, 'hot'” (2007, 33). Therefore, as soon as a museum constructs an emotional path for the visitor, ${ }^{7}$ the visitor becomes passive in experiencing such a spectacle. Péter Apor demonstrates this in his analysis of the permanent exhibition (from 2002) in the House of Terror in Bu-

use of ethnographical methods in observing themselves and other visitors in experiential spaces in the Australian War Memorial (2014).

7 Often toward the political or didactic message that underlies the exhibition, via simulated authenticity, reduced visitor flexibility, and high narrativity. In other words the museum highlights one master narrative. 
dapest (2014). ${ }^{8}$ Apor notes "the dominance of audiovisual spectacle and the disorderly mixture of original and replica, authentic and scenery" that overwhelms the visitor emotionally $(2014,332)$. This also prevents the visitor from having interpretative freedom. The emotional feeling of "the authenticity of the experience of the past [is] irrespective of the authenticity of individual objects" (Apor 2014, 338). In contrast to such an emotional overwhelming of the visitor, the majority of recent theoretical approaches highlight the representational potential of the museum in forcing visitors out of their comfort-zone, showing its cool media qualities (e.g. Arnold-de Simine 2013, 2; Thiemeyer 2010a, 249; Crane 1997, 33).

In providing a close reading of the performative space of an exhibition, it is useful to employ the concept of distantiation and historical distance, as developed by Mark Phillips. Traditionally, historical practice has been defined by historical distance as "a position of detached observation made possible by the passage of time” $(2011,11)$. Distantiation is a tool to gauge how close or far a visitor is brought to the historical processes and experiences of the past. ${ }^{9}$ Phillips sees four distinct but overlapping modes as a constitutive part of every representation of history for historical authors and readers: "whatever its genre, [it] incorporates elements of making, feeling, doing, and understanding - or (to alter the terms) questions of formal structure and vocabulary, affective impact, moral or ideological interpellation, and underlying intelligibility" $(2013,6)$. In this way, historical distance does not merely imply detachment or separation between past and present; it can be seen in relational terms on a sliding scale, "into a continuous gradation made up of all positions from near to far" (Phillips 2013, 6). Historical distance works as a descriptive tool to demonstrate how human beings operate in the world "in relation to gradations of time, space, affect, or to the rewards and pressures of community" $(2013,12){ }^{10}$

For the analysis of the spatial language of exhibitions and their representational effects on the potential museum visitor, Phillip's concept of distantiation proves useful in numerous ways - even if he shapes his concept mainly to describe the historian's authorial perspective and the structure of text. How do war museums create proximities and distances between the past and the visitor in the present? ${ }^{11}$ If one takes aerial warfare in the Second World War, for example, how does a museum create emotional proximity or distancing when repre-

8 The House of Terror represents the fascist and communist regimes in twentieth-century Hungary in an experiential way, generally highlighting Hungarian victimhood.

9 For the function of narrative in this process see Bal 2008, 26.

10 For its relevance for memorial museums see also Williams 2007, 258.

11 For the application of Phillips's own approach to museums see also his analysis of the Canadian Museum of Civilization (now Canadian Museum of History) in Ottawa (2013, 211-218). 
senting past events and exhibiting historical objects? Do visitors empathize, sympathize or identify with individuals or collectives from the past? Or is it more likely that they will feel an unbridgeable gap to such experiences? The range of historical distance is as wide ideologically as it is emotionally. Is the visitor led into confirming or questioning frames and traditional narratives of the Air War? Can the visitor's interaction with the museum create an ideological rethinking of her or his own position, or does it confirm or reinforce the knowledge and prejudices she or he had before the visit? Cognitively, visitors can be so close to the past events of the Air War that an understanding of the overall historical processes is impossible. Furthermore, their understanding of the past can be steered toward a predominantly historical understanding (proximity) with a high degree of historical specificity, toward a predominantly anti-historical understanding of universal suffering in the Air War, or toward the heroism and sacrifices of the pilots and aircrew members. The latter creates distance on the cognitive level, but possibly highly affective and/or ideological proximity. To further understand the dynamics of a performative museum space in which the visitor operates according to different distantiation techniques, the second half of this chapter discusses how constructed or performed experience of the past the Second World War and its historical agents - can overlap with present experience. It also examines how this leads to a sliding scale between primary and secondary experientiality.

\subsection{Experientiality}

The concept of experientiality in history museums helps immensely in understanding the narrative, experiential, and representational possibilities and limitations of the medium of the (history) museum. It allows us to understand the natural difference, but also the dynamic overlap, between the visitor's experience as part of the performative nature of the museum and the historical experience of individuals and collectives. This subchapter explains two conceptual differences: first, the difference between experience and experientiality, and second, the difference between primary and secondary experientiality. With the advent of cognitive theory in narratology (for museums see Fulda 2005; Lippert 2009, 2010; Jaeger 2019), experientiality has become an important category in the discussion of the representation and narration of history. When representing the past one never discusses experiences of the 'real' past, but instead, in the words of Jonas Grethlein, the "experiences of experiences" (2010, 220). Monika Fludernik introduced the term experientiality into narratological research by defining narrativity as representation of experientiality (1996, 20-43). 'Natural' 
narratives cognitively correspond to human experience. Experientiality is "the quasi-mimetic evocation of 'real-life experience"' (Fludernik 1996, 12). Fludernik's emphasizes that the most important cognitively relevant factor for experientiality is "the presence of a human protagonist and her experience of events as they impinge on her situation or activities" (1996, 30). The protagonist reacts emotionally and physically to the experiential situation. Consequently, experientiality always implies an anthropomorphic experiencer, the protagonist's consciousness (Fludernik 1996, 30).

Regarding historiography, Fludernik argues that "[t]he experientiality of the source is [...] sublimated and transformed into collective experience as the historical object of analysis" (Fludernik 2010, 41-42). Originally, Fludernik strictly differentiated historiography from fiction and 'life-writing,' and maintained that:

historical narrative displays a degré zéro of narrativity since the purpose of historical narrative is not to portray the experience of individual characters that will allow readers to make sense of life by vicarious projection into the situation of a fictional protagonist, but the function of history is to provide an argument about what happened and why it did so, and how this relates to the present-day situation. (2001, 93, see also 1996, 328)

Fludernik has softened this differentiation in her later research, but has continued to maintain that historiographic narrative can merely express experience, not experientiality $(2010,70)$. There is no doubt that any form of historical experience is mediated and constructed. Museums, on the one hand, construct, simulate, and stage the past. On the other, visitors complete the museum experience with their own individual perceptions, selections, and routes through the museum space. This means that Fludernik's argument for scholarly historiography, in which the historian synthesizes knowledge in such a way that the experience is always mediated and secondary, does not work for the museum. The museum creates a different hybrid between historical experience and visitor experience, making "the quasi-mimetic evocation of 'real-life experience"” (i.e. experientiality) a particularly interesting concept with which to describe the representational potential of exhibitions.

In order to express historical experiences, museums can quote ego-documents from diaries, autobiographies, letters, interviews, and other sources. These are usually arranged in an argumentative or aesthetic ensemble and have a predominantly illustrative function. The term 'experientiality,' however, becomes useful when the idea of experiential consciousness is present in the act of reception. Researchers working with Fludernik's concept of experientiality have criticized it for seeming too rooted in narrative structure and underestimating the act of reception and the reader (Caracciolo 2014, 47-48). The interaction of narrative and reception needs to be considered in order to make this concept 
useful to museums. If one recognizes that historiography always produces constructed, simulated experiences, Fludernik's “quasi-mimetic evocation of reallife experience" shifts from the individual to the collective. A collective perspective is always a retrospective construct, since humans can feel like they are part of the collective, but they can never have a collective perception in the present moment.

Consequently, in the museum, the visitor becomes significant as a mediator - an anthropomorphic experiencer - for experientiality. An exhibition constructs a simulation effect, with the result that the visitor experiences the past as a collective human consciousness. This can include experiencing the collective effort of Canadians on the home front, the German's collective fascination with ideas of National Socialism, the fear of Belgian civilians under occupation, or the will to resistance in any occupied country. Since historiography, including museum representations of history, cannot reproduce the past or past worlds as such, this means that all primary 'quasi-mimetic' effects are constructed and simulated. The visitor reacting to the exhibition's spatial-temporal semiotic structure overlaps with historical entities who experienced the past as either individuals or constructed collectives. The ability to simulate experientiality is particularly interesting since museum visitors enter a space and scenery, taking over the role of an entity who has had a real life experience, which Fludernik primarily sees in fictional characters and real-life individuals (such as the writers of an autobiography). At the same time, there is no need to equate the visitor experience with any historical experience, since an exhibition clearly cannot equate the two. Therefore, experientiality becomes the analytical concept with which to examine the representational and narrative potential of an exhibition.

If a museum such as the Oskar Schindler Factory in Kraków creates a scene like that of a film-set, there are nevertheless no fictitious characters. However, visitors become like space and time travelers; they possess and express the consciousness needed to perform the experientiality of the museum. ${ }^{12}$ Even if a museum has a strong master narrative, as exemplified by the Warsaw Rising Museum, it still requires the visitor to generate experientiality in the space of the exhibition - in this case, the visitor is steered toward feeling empathy with the insurgents of the Uprising. ${ }^{13}$ There is experientiality here, but it is restricted by a strong ideological narrative. Therefore, even if experientiality originates in the exhibition's construct of text, narrative, and space, as designed by curators, interior exhibition designers, and architects, the concept of the 'ideal' museum

12 See also chapter 4.3.

13 See also chapter 3.2. 
visitor as mediating consciousness is needed to understand exhibitions' experientiality. Consequently, the need for analyzing the impact of reception in the museum is more intense than in other historiographical media. Whereas in fiction, an analysis could ignore the reader's responses and fully focus on the production and constructive nature of a text, the analysis of experientiality between exhibition and visitor is mandatory for understanding the representational effects of an exhibition. Experientiality, as developed by Fludernik for non-historiographical forms of narrative, becomes a particular important category for historical museums. An exhibition - as with any historiographical representation can quote from the historical sources of ego voices: those of individuals who express their own experience of historical events autobiographically. In contrast, primary and secondary experientiality in a museum are always simulated. This differentiates experience and experientiality.

Daniel Fulda was one of the first researchers to apply insights from natural and cognitive narratology to the medium of the museum by analyzing the narrative of the Wehrmacht Exhibition (Wehrmachtsausstellung). ${ }^{14}$ He uses the concept of narrativity in cognitive narratology to demonstrate the experiential potential of narrative exhibitions: "Cognitive narratology not only describes narrativity within the structure of artifacts but goes beyond this to investigate the way that such artifacts are cognitively processed, with the consequence that entire worldviews emerge within the consciousness of their recipients" $(2005,181)$. Fulda explains the scandal of the exhibition (see also Thiele 1999) by its lack of narrative contextualization. "[I]ts decontextualizing and singularly instrumental narrative structure” $(2005,186)$ could easily be countered with visitors' personal, autobiographical stories. What Fulda identifies as "singularly instrumental narrative structure" closely relates to the term 'restricted experientiality' as used in this analysis, though one can argue that exhibitions with restricted expe-

14 The full title of the traveling exhibition is War of Annihilation: Crimes of the Wehrmacht 1941 to 1944 (Vernichtungskrieg: Verbrechen der Wehrmacht 1941 bis 1944). It was organized by the Hamburg Institute for Social Research (Hamburger Institut für Sozialforschung) and shown in more than thirty German and Austrian cities between 1995 and 1999. The public debates and conflicts about the photography-based exhibition on war crimes of the Wehrmacht led to the intense debate about German perpetration and led German cultural memory of the war toward the universal acceptance that the Wehrmacht as an institution was heavily involved in the crimes and atrocities in the Second World War. The exhibitions of the Bundeswehr Military History Museum, the Topography of Terror, and the German-Russian Museum would not be possible without the transformation of public memory as result of the Wehrmacht Exhibition during World War II (see Mösken 2007; Thiemeyer 2019, 35-38; and Nugent 2014 for an empirical visitor studies approach by analyzing the exhibition's visitor books). 
rientiality generally rely openly on a single dominating narrative structure. ${ }^{15}$ Consequently, Fulda follows Fludernik's equation of narrativity and experientiality more closely than my study does. He is more interested in the potential of narrative in general, for which the exhibition functions as a case-study than in exploring the specificity of the medium 'museum.'

To understand the decisive second distinction between primary and secondary experientiality, it is first important to explain the concept of simulation, since it leads to the core of experiential challenges in the museum. Museums in general fail to represent the 'real' past; Jay Winter argues that war museums by definition fail to represent war, "because there was then and is now no consensus as to what constituted the war" $(2013,23)$. They can only "represent the traces and trajectories of collisions that happened a long time ago. They never describe war; they only tell us about its footprints on the map of our lives" (Winter 2013, 23). Whereas a novel or feature film would allow the visitor to dive imaginatively into a fictional world, in a museum, the visitor mainly remains safely in a visitor position. Museum buildings are not a natural environment for representing war. Visitors pay admission; they know they can come and leave at their leisure; they decide how much time to spend in the galleries; they make decisions concerning what texts, images, artifacts, and scenographic installations they actually pay attention to and choose how long they linger in certain exhibition sections. Consequently, the representational act of 'simulating' a specific historical scene or experience always pretends to act out an impossible illusion of 'imitating' the past. This never goes as far as Jean Baudrillard's postmodern thesis about the disappearance of the real or authentic in today's media age, wherein everything becomes a simulation (1994 [1981]). ${ }^{16}$ History museums can never reproduce historical experiences and atmospheres, which ensures that the visitor can only experience the 'original past' as a simulation, an illusion of a presence, or by assuming the museum stages an illusionary proximity to the past. The mimetic relationship to the past remains critical in any museum simulation of the Second World War.

15 Fulda reads the revised Wehrmacht Exhibition (2001-2004, renamed Crimes of the German Wehrmacht: Dimensions of a War of Annihilation 1941-1944 = Verbrechen der Wehrmacht. Dimensionen des Vernichtungskrieges 1941-1944) as still lacking narrative, since it did not offer insight into a continuous sequence of events, but he interprets its deep structure as narrative "since it contextualizes at every turn" $(2005,188)$.

16 For a detailed summary of the rhetorical concept of 'simulation' (simulatio) from antiquity to its postmodern understanding, see Dotzler 2010 [2003]. 
As discussed above, ${ }^{17}$ visitors can be temporarily overpowered by media and forget that they are experiencing a simulated historical scene as a virtual reality. They imagine the historical scene and suspend their reflective judgments. This helps us to understand Alison Landsberg's concept of 'prosthetic memory,' which implies that mass media such as film and experiential museums can create sensuous, bodily memories that do not come from lived experience, but from engagement with mediated representations (2004) ${ }^{18}$ In Landsberg's theory, there is clearly a mimetic connection to the past that allows visitors to experience secondary memories. For example, Landsberg argues that in the United States Holocaust Memorial Museum, visitors, realizing that they are walking on actual cobble stones from the Warsaw Ghetto, are enabled to forget the distinction between safe museum space and their own bodily reaction - connecting them empathetically to history $(2004,132)$. Even authentic objects from the past, observed from a distance, draw visitors through "their very materiality [...], their seductive tangibility" into a "lived relationship with them" (Landsberg 2004, 132). The concept of simulation helps to understand Landsberg's concept in a wider context; there is no need for mimetic equivalency, but the resemblance of present and past with a "seductive tangibility" allows - in Landsberg's case - for forms of secondary witnessing of past traumas.

When representing war and atrocities, the representation of trauma works as a powerful example to further understand the difference between primary and secondary experientiality. Can a visitor really empathize with the trauma and anxiety of historical groups? How can the presumably 'safe' museum relate to the realness of trauma that exists beyond representation through a historiographical and objectifying narrative, without taking "the trauma out of trauma?" (LaCapra 2016, 377). Dominick LaCapra argues that structural trauma can express transhistorical absence and is an anxiety-producing condition of possibility (2001: 84-85; see for trauma in the war museum also Jaeger 2017c, 146-147). To circumvent postmodernist skepticism, trauma must be viewed as "existing outside conventional forms of perception, representation and transmission," with the Holocaust in particular as the central traumatic event in the twentieth century and "the last example[] of the 'real"' (Arnold-de Simine 2013, 35). LaCapra identifies two secondary experiences of trauma: vicarious and virtual experiences (2004: 125). Vicarious experiences can lead to confusing one's participation in the traumatizing events through identification with the victim, whereby one

17 See also chapter 1.3.

18 See also Bedford 2014 for practical techniques to evoke and imagine the past through stories, aesthetic experience, immersive environments, and unique artifacts for the museum visitor. 
becomes a surrogate victim. In the museum context, this is most likely to occur at authentic places of historical, traumatic events, such as a memorial site at a Nazi concentration camp. However, as demonstrated, for example, by Julia Rose's concept of Commemorative Museum Pedagogy for representing difficult knowledge in museums, such surrogate victimhood is to be avoided through the development of ethical standards of representation (2016, especially 99134). In LaCapra's concept of the virtual experience of trauma, one may imaginatively put oneself in the victim's position, while respecting the difference between self and other and recognizing that one cannot take the victim's place or speak in the victim's voice: "Such virtual experience may be connected with what I have termed empathetic unsettlement, which, I would argue, is desirable or even necessary for a certain form of understanding that is constitutively limited but significant" (LaCapra 2004, 125). LaCapra sees empathetic unsettlement as "a barrier to closure in discourse" that creates a certain discomfort in "inhabiting' the experiences of others $(2001,41)$.

The challenge in simulating history in the museum is to understand whether, or to what degree, a given museum representation pretends to simulate possible realistic perspectives that historical people in the past could have had, or whether the simulation relates to structures that do not have a direct equivalent in the past but contribute to the understanding of past structures and atmospheres or memory patterns at a later stage. This leads to an understanding of primary and secondary experientiality on a sliding scale. In all of their forms, primary and secondary experientiality are simulations; both pretend, in different ways, to bring the visitor close to the past. Visitors are - presumably - aware that they are not experiencing the past as historical contemporaries experienced it; yet museum techniques can help to simulate historical experience and create experientiality with the effect that the visitor understands and possibly feels how an individual or collective human consciousness might have perceived and experienced the past. Primary experientiality in a museum can therefore be defined as a simulation of actual historical events or of historical situations that demonstrates how members of a group could have experienced the past as such. It includes forms of empathy and reenactment that claim to mimetically bring the visitor close to historical experiences.

In contrast, secondary experientiality produces the effect of a collective historical experience without any equivalent that could be mimetically approached in the past; it is a simulation of abstract structures. Before I provide a range of examples for primary and secondary experientiality as well as hybrid forms that oscillate between both, it seems useful to provide one more detailed example. The 101st Airborne Museum Le Mess in Bastogne, features a basement shelter installation behind a steel door. The visitor finds a wooden stool and bench to sit 
on and experiences a 'live' air-raid, while watching a static diorama of a family, depicted through mannequins, hugging each other and apparently trying to survive the air-raid. ${ }^{19}$ Visitors experience a combination of light, vibration, and sound effects; they seem to be joining the family in experiencing the raid in a small, almost claustrophobic space. The light is shaky and at times it is completely dark. One hears coughing, shouting, and crying. The museum does everything to make this experience mimetically close to the historical one many people might have had on Christmas night in 1944, when Bastogne was bombed by the Germans. The bodily effects that the exhibit elicits, such as hearing the extreme noise in a small space, certainly makes it an uncomfortable experience that might allow the visitor to shift in part from an observational perspective to an experiential one. The exhibition simulates a primary experience, i.e. it creates the effect of primary experientiality of how a collective could have experienced an air raid in the Second World War. There is a clear historical referent; it is also clear that, unlike in a fictional or autobiographical account, the installation does not refer to one specific experience by one character or person in an air raid shelter, but to the collective experience of all civilians in Bastogne. ${ }^{20}$

Exhibitions that follow a mimetic pattern of creating experientiality are often highly focused on the reconstruction of presumably authentic scenes, which is usually connected to the belief in the authenticity of original objects and carefully / accurately arranged uniforms and weapons. Most often, visitors see dioramas with mannequins arranged into a particular war scene, which could either be a specific historical moment in war or a scene serving as example for a typical scene or activity in the war, such as a field hospital scene (see e.g. Jaeger

19 The museum praises itself as "a realistic authentic war museum" (http://www.101air bornemuseumbastogne.com/, accessed 13 October 2019). I visited the museum on July 4, 2014. 20 The Airborne Museum 'Hartenstein' in Oosterbeek near Arnhem, tells the story of the Battle of Arnhem as part of the Allied operation Marketgarden in September 1944. In 2009, on the sixtyfifth anniversary of the Battle of Arnhem, the museum opened the new Airborne Experience in its basement. The visitor walks through a number of dioramas and between large poster walls of the battle, supported by audio-visual means, including a mission briefing, and entering and exiting of a glider. Since the exhibition lacks narrative features that enhance the perspective of the visitor as a young British parachutist, the potential for primary experientiality is limited. This means that the installation remains static and the visitor a passive observer. During a visit in August 2019, most visitors were moving quickly through the different scenes, without engaging with the potential experiential perspectives that the Airborne Experience wants to create: "The underground Airborne Experience showcases the war in all its intensity. Here you will feel the impact of the violence on the young boys who were desperately fighting for their lives" (https://www.airbornemuseum.nl/en/exhibitions/airborne-experience, accessed 13 October 2019). 
2017b, 167-168). This representational technique remains mostly static; the visitor is a passive observer. On the one hand, such representations are typical of older museum exhibitions that predate the digital age. On the other, they are typical of collector museums up to today (see also Jaeger 2019, 55-58). For example, the Overlord Museum in Normandy near Omaha Beach ${ }^{21}$ is completely based on dioramas, although it only opened in June 2013. If the viewer is simply an observer of a diorama that pretends that a reconstructive view of history is possible, the scene is usually static and the visitor cannot therefore become directly part of it. Often, such reconstructive scenes are connected to the desire for authenticity, of being physically at a historically authentic space. This could be the case when a visitor enters the Imperial War Museum's Cabinet War Rooms (now Churchill War Rooms) in London, from where Churchill orchestrated British activities in the Second World War. There is nothing experiential here, except for the feeling of authenticity based the Cabinet War Rooms' function as an 'auratic' place in the mode of witnessing authenticity (Pirker and Rüdiger 2010, 17; Sabrow and Saupe 2016). How it is refurbished or reconstructed is probably of secondary interest to the primary feeling that one is standing in the 'real place.'

Whereas older exhibitions try to reconstruct historical scenes and spaces to allow the visitor to enter history, most museums today avoid this static form of immersion. The more dynamic the representation is, the more likely it is that its exhibitions produce experientiality. Astrid Erll and Ann Rigney differentiate accordingly, in their approach to mediation and remediation, between 'immediacy' that expresses the experience of the presence of the past and 'hypermediacy' that reminds the recipient of the medial and constructed character of the medium, potentially producing self-reflexivity $(2009,4)$. In all cases of immersion into history in the museum, the visitor will need a certain amount of imagination to connect past and present. For variations of primary experientiality, the visitor can be made fully aware of the artificiality of the setting and more emotionally steered toward a certain perspective that usually reproduces the collective gaze of a group. This often happens in theatrical settings, which allow the visitor to enter a scene designed through interior architecture, as can be seen in detail in the analysis of the Oskar Schindler Factory later in this study. ${ }^{22}$ For example, visitors enter the staged Old Market Square of Kraków in 1944. They walk between transparent plexiglass panels, which are spread throughout the room and that tell different stories of historical people in Kraków representing typical groups and types from that era. The reduction of mannequins to transparent fig-

21 Visited on June 20, 2015.

22 See chapter 4.2. 
ures in space is part of the negation of a simplistic mimetic model of experience and allows for the creation of a stronger primary experientiality (in which the visitor plays a role). Visitors can explicitly feel the distance between themselves and the historical place and time, creating a potential for reflection. This allows visitors to consider what they know about the historical persons represented in the exhibition and what they stand for. In contrast, the reconstruction of an allegedly correct or at least probable past might help the visitor to remember specific historical facts or scenes that model specific types of war activities, which makes it easier to understand the different elements of war. However, visitors in this case remain passive, observing constructed examples of the war, authenticated through the sheer mimesis of objects or by the authenticity of the space. This often confirms myths and stereotypical patterns of cultural memory. Immersing a visitor directly into a scene of the past is closer to a playful trick whose function is to attract higher visitor numbers via entertainment, rather than bringing them closer to experiencing the war and empathizing with real historical people. Consequently, such reconstructive approaches are unlikely to create primary or secondary experientiality for the visitor; they simply mirror the past without integrating visitors and do not require their imagination.

Secondary experientiality is produced if an exhibition creates structural experiences in which the museum visitor cannot simply empathize with the role of an individual as part of a historical collective. It constructs an experiential space that is clearly differentiated from a past reality as a construct of traces and forces of the past, which only comes into being in the poietic act of museum representation. There is no direct referent in the past if a museum simulates the effect of force, power, and violence in war, as will be analyzed in detail below for the Bundeswehr Military History Museum in Dresden. ${ }^{23}$ If a museum stages the suffering of civilians in the Second World War, such as the Gdańsk Museum of the Second World War, secondary experientiality can be felt; however, no referent to 'the' experience of civilians or to 'the' experience of German behavior in the last days of the war exists.

Because primary experientiality is as simulated as secondary experientiality, I argue that almost all museums today construct their own simulated historical, poietic worlds (see also Jaeger 2011, 31-33) 24 $^{4}$ and thereby their own experientiality, although they vary in their representational strategies. To understand these strategies, it is crucial to examine the varying degrees of primary and secondary

23 See chapter 5.1.

24 See also Jaeger 2011, 44-46 for initial thoughts on the poietic character of exhibitions by example of the Oskar Schindler Factory. 
experientiality. Examples of these strategical variations include historical distance between visitor and museum content, focus on individual voices and collective perspectives, and use of narrative and scenography. A museum can expand the notion of time and space, which leads to a dynamic relationship between history and memory and additionally involves visitors in terms of their future behavior through different emotional, moral, reflexive, and pedagogical dimensions. However, the concept of experientiality allows for the development of a theoretical framework to understand the possibilities contemporary museums hold for mediating war as well as how they generate aesthetic and emotional responses. Experientiality and the simulation of historical atmospheres can be created at authentic battleground locations and in more abstract museum contexts separated from concrete historical events.

It is also evident that the differentiation of primary and secondary experientiality must be discussed on a sliding scale. There is secondary experientiality that is explicitly based on a composite of primary experiences; consequently, empathy and reenactment can also be significant museum techniques to simulate collective perspectives, as exemplified in the Imperial War Museum North, in which voices of children's experiences of different wars create new structural experiences for the visitor. Additionally, there is secondary experientiality when a museum simulates historical structures that can only become experiential when reproduced in historical representation, such as in "The Economy of War in World War II" cabinet on the German armament industry and economy of the Second World War in the Bundeswehr Military History Museum. The cabinet does not merely document the links between the economy, war, and Holocaust; rather, it makes them present, so that the visitor has no doubt about the historical complicity of German society and industry in the Holocaust and the interwovenness of the war effort and Holocaust. The cabinet also contributes to the visitor's general understanding of war and atrocity by letting them experience the interwovenness of the different components that allow war to happen and which sustain it (see also Jaeger 2015b, 238).

The category of experientiality allows us to dissolve this extreme dichotomy between experiential and object-based history museums. It makes it possible to more precisely analyze whether a museum is historical or present- and futureoriented. The four core theoretical elements of this study - restricted experientiality, primary experientiality, secondary experientiality, and transnational memory - do not automatically define which representational techniques a museum, which follows a certain tradition or has a certain political agenda in memory politics, chooses. Therefore, the House of European History might use similar strategies to the Warsaw Rising Museum, the Imperial War Museum North, and the Bundeswehr Military History Museum. However, once one distinguishes be- 
tween primary and secondary experientiality, it is possible to analyze numerous museum techniques that create experientiality and that do not fall in the trap of the naive mimetic experience model. Instead, exhibitions can perform experientiality in nuanced ways between representing historical knowledge, using the authenticity of artifacts and locations, constructing individual and collective experiences, simulating historical structures, and emotionalizing the visitor on different levels.

To create experientiality, an exhibition must go beyond simply presenting facts and objects. If the historical context is strongly restrictive, this leads the visitor to read every theme within a prescribed narrative or ideological frame. This, in turn, strongly reduces the possibility of integrating the visitors' present perspectives and providing room for their affective, ideological/ethical, and cognitive capacities. The less the visitor is steered toward one ideological or ethical message, and the more that a museum uses networking techniques and creates traces, tensions, and open constellations, the more likely it is that an exhibition will develop the potential for experientiality. The museum must ensure that it provides the basis for clusters and constellations. It needs to go beyond a pre-determined linear path and - at least in addition to a linear structure - set up thematic and historical clustering throughout its exhibition.

Such networking techniques can be philosophically connected to models of time that highlight simultaneity. From a modernist, progressive perspective, Reinhart Koselleck argues in Futures Past, that under the condition of accelerating temporality in modernity, the "space of experience" and the "horizon of expectation" redouble "past and future on one another in an unequal manner" (2004 [1979], 263). Applying Koselleck's metaphor of "sediments of time” (2018 [2000] $)^{25}$ to twenty-first-century museums, in particular to the Ruhr Museum in Essen, Kerstin Barndt demonstrates how museums today can represent the multi-temporal dimensions of time, a kind of "synchronous multitemporality that relies on a dialectical relation between historical events and anthropologically grounded, repetitive structures" (2010, 138). Wulf Kansteiner has employed the metaphor of a "chronosophic net" that does not operate in a chronological or linear way, but rather multidimensionally, so that Holocaust narratives can deal with their representational challenges between history and memory in the twenty-first century $(2013,23) .{ }^{26}$ Although Hans-Ulrich Gumbrecht applies a postmodern temporal concept that seems to be the exact opposite of Koselleck's modernist progressive one, the results with regard to exhibiting the Second World War in

25 "Zeitschichten" in German.

26 See also chapter 7. 
twenty-first-century museums are surprisingly similar. Gumbrecht argues for a new chronotype, a "broad present" (Gumbrecht 2014). There is no entrance or exit to this ever increasing broad present. According to Gumbrecht, the chronotype is rooted in the immediate aftermath of the Second World War, but is only fully at work in the early twenty-first century (2013). Following Gumbrecht's model would negate the effort of many action and progress-oriented ideas museums, such as the Canadian Museum for Human Rights, or the action-related comparative sections of the United States Holocaust Memorial Museum. In contrast, to exhibit, represent, and narrate the Second World War, the difference is less relevant, since almost all museum exhibitions operate in the constant dialogue between past and present - the latter personified through the museum visitor. If an exhibition develops an active dialogue between past and present, visitors are challenged to become part of the past. They do not enter a 'museum temple,' representing a past that is explicitly kept distant from them. Instead, this process then integrates past and present, memory and history, and exhibitions can develop simultaneities and numerous temporal layers. Visitors who find and interpret such constellations and simultaneities that create the exhibition's experientiality must - to a certain extent - decide for themselves whether these constellations indicate a cultural-historical development and perhaps even progress (Koselleck), or an endless cycle with no substantial change (Gumbrecht).

One example of a temporalized cluster in the museum is the cluster of 'humiliating otherness' in the permanent exhibition of the Topography of Terror in Berlin, analyzed below. ${ }^{27}$ The documentation center creates numerous systemic networking effects through clustering and the visualization of aspects such as the spectatorship of crimes, scenes of denunciation, scenes of deportation, and mass scenes in general, that allow a dynamic re-arranging of chapters of the museum by the potential visitor. Similarly, the Imperial War Museum North in Manchester mainly depicts historical topics, yet certain themes such as children and war, or the civil war experience, are interwoven in all dimensions of its permanent exhibition, so that they receive a structural, secondary quality. ${ }^{28}$ Networking can happen with thematic concepts, such as war and suffering and with historical themes, such as aerial warfare in the Second World War or the Holocaust. The visitor can find - possibly encouraged through hints by the museum - other paths and constellations. On the one hand, museums can challenge an active visitor to interpret the material instead of passively

27 See chapter 5.3.

28 See chapter 5.2 . 
perceiving it. On the other, they must provide the visitor with enough historical context so that different readings are actually possible. If, for example, the visitor merely sees images of suffering that seem similar, an exhibition lacks the historical specificity for the visitor to make connections between them. The visitor might just take away a general message of the universality of suffering. In other words, a networking technique that balances thematic and conceptual issues with historical specificity is more likely to develop experientiality.

To further understand the variations of representational techniques that create or restrict experientiality and to see details of the variations of the sliding scale between primary and secondary experientiality, a close reading of the semiotic, narrative, and aesthetic performances of time and space that an exhibition can offer the visitor is needed. I examine the variety of temporalized acts in the museum that create or reflect cultural memory of the Second World War in the medium of the historical museum, with a focus on the following theoretical concepts that structure my analysis of the twelve museums under study in chapters three to six: restricted experientiality, primary experientiality, secondary experientiality, and the transnational. 